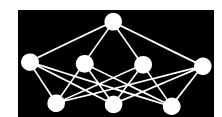

\title{
THE USE OF SELF-ORGANIZING FEATURE MAP NETWORKS FOR THE PREDICTION OF THE CRITICAL FACTOR OF SAFETY OF AN ARTIFICIAL SLOPE
}

\author{
Y. Erzin, M. Nikoo ${ }^{\dagger}$ M. Nikoo
}

\begin{abstract}
In this study, the performance of three different self organization feature map (SOFM) network models denoted as SOFM1, SOFM2, and SOFM3 having neighborhood shapes, namely, SquareKohonenful, LineKohonenful, and DiamondKohenenful, respectively, to predict the critical factor of safety $\left(F_{\mathrm{s}}\right)$ of a widely-used artificial slope subjected to earthquake forces was investigated and compared. For this purpose, the reported data sets by Erzin and Cetin (2012) [7], including the minimum (critical) $F_{\mathrm{s}}$ values of the artificial slope calculated by using the simplified Bishop method, were utilized in the development of the SOFM models. The results obtained from the SOFM models were compared with those obtained from the calculations. It is found that the SOFM1 model exhibits more reliable predictions than SOFM2 and SOFM3 models. Moreover, the performance indices such as the determination coefficient, variance account for, mean absolute error, root mean square error, and the scaled percent error were computed to evaluate the prediction capacity of the SOFM models developed. The study demonstrates that the SOFM1 model is able to predict the $F_{\mathrm{S}}$ value of the artificial slope, quite efficiently, and is superior to the SOFM2 and SOFM3.
\end{abstract}

Key words: critical factor of safety, earthquake forces, pseudo-statistic approach, Self Organization Feature Map, simplified Bishop method

Received: June 15, 2014

DOI: $10.14311 / N N W .2016 .26 .027$

Revised and accepted: September 9, 2016

\section{Introduction}

Slope stability analysis is an important area in geotechnical engineering [27]. The evolution of slope stability analyses in geotechnical engineering has followed closely the developments in the soil [24]. Slope failures are complex natural experience that comprises a serious natural hazard in many countries [32]. They are responsible for

\footnotetext{
*Yusuf Erzin - Corresponding author, Tulin Cetin, Celal Bayar University, Faculty of Engineering, Department of Civil Engineering, 45140 Manisa, Turkey, E-mail: yusuf.erzin@cbu.edu.tr

${ }^{\dagger}$ Mehdi Nikoo, Young Researchers and Elite Club, Ahvaz Branch, Islamic Azad University, Ahvaz, Iran

${ }_{\ddagger}$ Mohammad Nikoo, SAMA Technical and Vocational Training college, Islamic Azad University, Ahvaz Branch, Ahvaz, Iran
}

(C)CTU FTS 2016 
hundreds of millions of dollars of damage to public and private property every year [32]. Thus, it is very crucial to analysis the stability of slopes [22]. The factor of safety $\left(F_{\mathrm{s}}\right)$ based on an appropriate geotechnical model as an index of stability is required to evaluate the slope stability [23]. Failure surface is the most important in calculating of a minimum (critical) $F_{\mathrm{s}}$ against sliding or shear failure. The $F_{\mathrm{s}}$ for slope stability analysis is usually defined as the ratio of the ultimate shear strength divided by the mobilized shear stress at incipient failure [27]. Given a predefined slip surface, the $F_{\mathrm{s}}$ is determined from the equilibrium of force and/or momentum of the mass contained between the slip surface and the free ground surface [33]. Evaluation of a reliable $F_{\mathrm{s}}$ is one of the most difficult issues in soil and rock mechanics problems [23]. Many researchers have attempted to develop techniques for analysis and prediction of stability of slopes [23]. The slope stability analysis is mostly being performed under static loading conditions [22], but earthquakes are important triggering forces behind the instability of slopes in a seismically active region [18]. As a result, in these regions, it is also essential to carry out the seismic slope stability analysis [22]. The pseudo-static (PS) approach is the widely-used procedure used for seismic slope stability evaluation even though more advanced and rigorous methods of analysis are now available [3]. This approach has been implemented in various limit equilibrium methods in which earthquake effects are represented by an equivalent static force [1]. The limit equilibrium methods, in spite of having several well-known disadvantages, are still commonly used to estimate the stability of slopes [2]. These equilibrium methods satisfy either some or all of the equilibrium conditions which include: (1) some or all interslice forces [15, 19]; (2) moment and/or some forces [4, 31]; and (3) moment and all forces [25, 28, 29].

The Self Organization Feature Map (SOFM) has been originally developed by Teuvo Kohonen [21], and is a data analysis, visualization and interpretation tool that is based on the principles of vector quantization and measures of vector similarity [16]. A SOFM analysis can highlight subtle relationships and assist in the process of knowledge creation from complex and disparate data [16]. While most SOFM procedures can be considered exploratory, the method can be used to perform broad categories of operations such as, function fitting, prediction or estimation, clustering, pattern recognition or noise reduction, and classification [16]. In this study, three different SOFM models, with respect to the above advantages, were developed to predict the critical $F_{\mathrm{s}}$ value of a widely-used artificial slope subjected to earthquake forces. Keeping this in view, the data sets used by Erzin and Cetin [7], including the minimum (critical) $F_{\mathrm{s}}$ values of the artificial slope calculated by using the simplified Bishop method [4], were utilized in the development of the SOFM models. The performance indices such as the determination coefficient, variance account for, mean absolute error, root mean square error, and the scaled percent error were used to assess the prediction capacity of the SOFM models developed.

\section{Self Organization Feature Map (SOFM)}

Self Organization Feature Map (SOFM) network, a competitive learning method, is utilized for training which has been developed based on specific characteristics of 
human brain [26]. Cells in the human brain in various areas have been organized so those are presented with regular and important computational maps in different sensory areas. In a SOFM network, the processor units are in the nodes of onedimensional, two-dimensional, or more dimensional network [26]. In a competitive learning process, the units are regulated based on the input patterns. The location of the regulated units in the network regulated such that a significant coordinated system developed on the network for the input features. Thus, SOFM network develops a topographic map of input patterns, where the location of the units is corresponding to the intrinsic characteristics of the input patterns. Competitive learning employed in such networks is so that in each learning step, the units compete for activation. At the end of a stage race, only one unit wins, its weights are changed differently than the weights of the other units. This type of learning is called as unsupervised learning. SOFM networks are classified into several categories in term of structural features including, MaxNet, Mexican Hat, Hamming, and Kohonen network [26].

Kohonen learning law goes back to 1962 and before and unsupervised clustering discussions. In 1970s decade, Christoph Von Der Malsburg introduced a law based on the idea that the sum of input weights result from one specified output in various units must be constant [21]. The basis of this idea is the limitation of the existence chemical material in the input and its dividing between various inputs connecting to this input. $W_{i}$ vectors must be changed so that for each input vector $X$ with density function, the probability $\rho$ is as follows:

$$
\rho(X)=\frac{1}{m} .
$$

This idea ideally worked for uniform probability density functions. In 1987, Duane Desieno developed a change in the Kohonen law which resolved the mentioned problem. However, it is still called as Kohonen law because of the important role of Kohonen in this area. A Kohonen layer is a one-dimensional, two-dimensional, or higher array of neurons. A one-dimensional Kohonen network is given in Fig. 1.

In the learning phase in this network, the distances between the input vector $X$ and the corresponding weigh of each unit is calculated using Eq. (2):

$$
I_{i}=D\left(X, W_{i}\right),
$$

where $D$ is the measurement function. Each of the common functions can be used to measure the distance. For example, Eq. (3) shows the spherical arc distance [21]

$$
D(u, v)=(1-\cos \theta) .
$$

$D(u, v)=|u-v|$ can be used for measuring the angle between $u$ and $v$ or Euclidean distance. The units aim to know whether they have the closest weight vector to $X$ or not. This is the competitive part of this kind of networks. The unit with closest weight to the input vector will be the winner of this step of the competition for which $Z_{i}$ is equal to 0 . Then Eq. (4) represents the Kohonen law used to update the weights [21]:

$$
0<\propto w_{i}^{\text {new }}=w_{i}^{\text {old }}+\propto\left(X-w_{i}^{\text {old }}\right) z_{i} .
$$




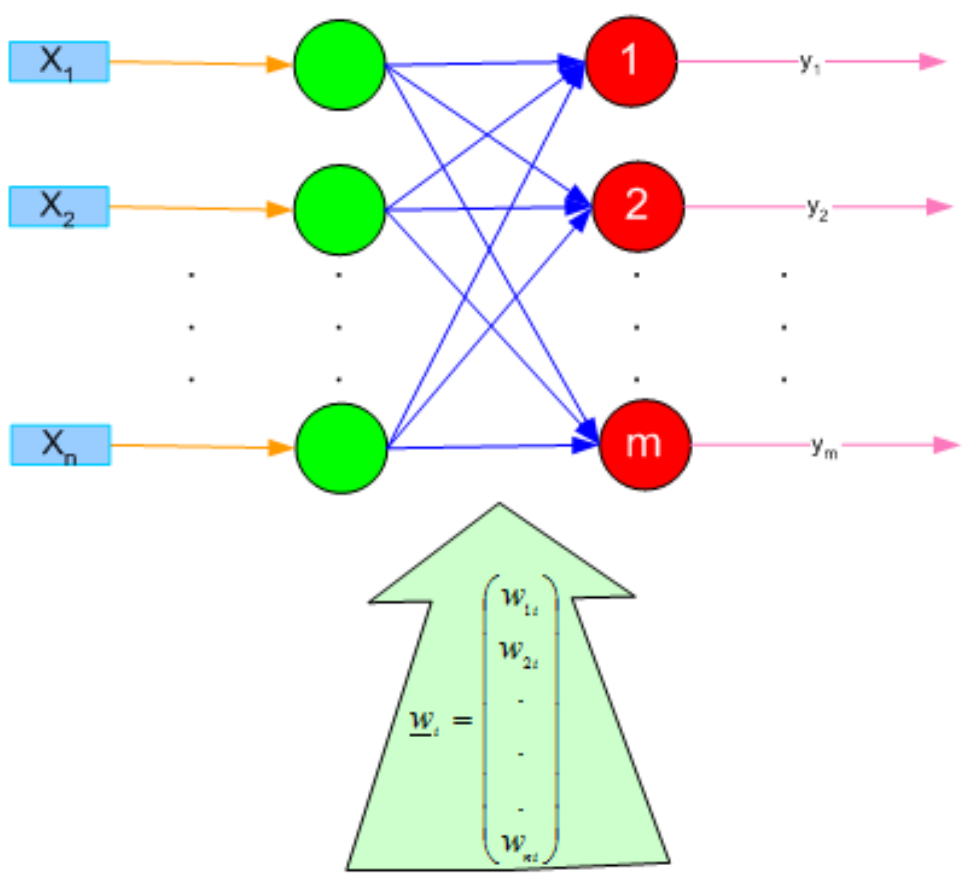

Fig. 1 One-dimensional Kohonen network structural model [26].

Then Eq. (5) is equivalent to Eq. (4):

$$
w_{i}^{\text {new }}=\left\{\begin{array}{ll}
(1-\propto) w_{i}^{\text {old }}+\propto x & \text { for winner } \\
w_{i}^{\text {old }} & \text { other units }
\end{array} .\right.
$$

\section{The data sets used in the development of the SOFM models}

In this study, the data sets reported by Erzin and Cetin [7], including the minimum (critical) $F_{\mathrm{s}}$ values of the artificial slope subjected to earthquake forces, were utilized in the development of the SOFM models. In Erzin and Cetin [7]'s paper, while the geometry of the slope and the properties of the soil involved in the slope are kept constant, the three soil properties, namely, bulk unit weight $(\gamma)$, cohesion $(c)$, and angle of internal friction $(\varphi)$ of the layer beneath the ground surface and seismic coefficient $(k)$, varied during the stability analyses. Then, in Erzin and Cetin [7]'s paper, the $F_{\mathrm{s}}$ values of the artificial slope were calculated by using simplified Bishop method [4] and the $F_{\mathrm{S}}$ value was then determined for each case by using the written program [5]. The details of the data used in the SOFM models are listed in Tab. I. 
Erzin T. et al.: The use of Self-Organizing Feature Map networks for...

\begin{tabular}{ccccc}
\hline Parameters used & Minimum & Maximum & Mean & Std. Deviation \\
\hline$\gamma$ & 16 & 22 & 19 & 2.2370 \\
$c$ & 5 & 50 & 27.5 & 14.3674 \\
$\varphi$ & 15 & 40 & 27.5 & 8.5427 \\
$\mathrm{k}$ & 0.1 & 0.5 & 0.3 & 0.1415 \\
$F_{\mathrm{s}}$ & 0.37 & 3.80 & 1.44 & 0.5899 \\
\hline
\end{tabular}

Tab. I The details of the data used in the SOFM models [7].

\section{Developed Self-Organizing Feature Map models}

In this study, three different Kohonen Self Organization Feature Map (SOFM) network models, denoted as SOFM1, SOFM2, and SOFM3, respectively, were developed to predict the critical factor of safety $\left(F_{\mathrm{s}}\right)$ value of the widely used artificial slope subjected to earthquake forces. SOFM1, SOFM2, and SOFM3 models have neighborhood shapes, namely, SquareKohonenful, LineKohonenful, and DiamondKohenenful, respectively. The three soil parameters of the layer beneath the ground surface, namely, the bulk unit weight, $\gamma$, cohesion, $c$, and angle of internal friction, $\varphi$, and seismic coefficient $k_{\mathrm{h}}$ were used as the input parameters in the SOFM models. The calculated $F_{\mathrm{s}}$ value was utilized as the output parameter. To avoid overfitting, the database was randomly divided into three sets: training, testing, and validation. In total (i.e., 1190 data sets), $70 \%$ of the data (i.e., 834 data sets), $15 \%$ (i.e., 178 data sets), and $15 \%$ (i.e., 178 data sets) were randomly selected and used for training, validation, and testing sets, respectively, in the SOFM models developed in this study.

Different excitation functions including LinearAxon, BiasAxon, LinearSigmohidAxon, LinearTanhAxon, SigmohidAxon, TanhAxon were utilized to determine the best structure of the SOFM models. The number of the nodes in the hidden layer(s) was determined by the following empirical formula (6) [17]:

$$
N_{\mathrm{H}} \leq 2 N_{\mathrm{I}}+1,
$$

where $N_{\mathrm{H}}$ and $N_{\mathrm{I}}$ are the number of nodes in the hidden layer(s) and input layers, respectively. Different learning algorithms, namely, Momentum, Delta-bar-delta, and Quick prop, were used to search for the most efficient SOFM structure in each SOFM model. The genetic algorithm was used to intelligently decide the initial weights and the competitive learning for the further unsupervised training. Then, the optimal structure of each SOFM model was determined through software ver 5.0 NeuroSolutions. Tab. II summarizes the optimal structure of each model and their various characteristics obtained from genetic algorithm. 
Neural Network World 5/2016, 461-475

\begin{tabular}{lccccc}
\hline Model & Neighborhood Shape & $\begin{array}{c}\text { The number } \\
\text { of hidden } \\
\text { layer(s) }\end{array}$ & $\begin{array}{c}\text { The number } \\
\text { of the nodes in the } \\
\text { hidden layer(s) }\end{array}$ & $\begin{array}{c}\text { Learning } \\
\text { algorithm }\end{array}$ & $\begin{array}{c}\text { Transfer } \\
\text { function }\end{array}$ \\
\hline SOFM1 & SquareKohonenfull & 1 & 9 & Momentum & TanhAxon \\
SOFM2 & LineKohonenfull & 2 & $5-4$ & $\begin{array}{c}\text { Delta Bar Delta } \\
\text { LinearAxon } \\
\text { Quickprop }\end{array}$ & SigmoidAxon \\
\hline
\end{tabular}

Tab. II The optimal structure of each SOFM model and their various characteristics obtained from genetic algorithm.

\section{Results and discussion}

The $F_{\mathrm{s}}$ values calculated from the Simplified Bishop Method [4] were compared with the $F_{\mathrm{s}}$ values predicted from the SOFM1 model, as shown in Fig. 2 for training, validation, and testing samples. The solid diagonal line in Fig. 2 represents a perfect prediction line. The lower line represents a $100 \%$ over prediction bound and the upper line represents a $50 \%$ under prediction bound. Approximately all of the predictions in Fig. 2 fall onto or are very close to the 1:1 line, which indicated that the predicted $F_{\mathrm{s}}$ values of are good agreement with the calculated $F_{\mathrm{s}}$ values. As a result, the critical $F_{\mathrm{s}}$ value of the homogeneous finite slope considered in this study could be predicted by utilizing the trained SOFM1 structures as quite easily and efficiently.

The $F_{\mathrm{S}}$ values calculated from the Simplified Bishop Method [4] were compared with the $F_{\mathrm{s}}$ values predicted from the SOFM2 model, as illustrated in Fig. 3 for training, validation, and testing samples. The solid diagonal line in Fig. 3 represents a perfect prediction line. The lower line represents a $100 \%$ over prediction bound and the upper line represents a $50 \%$ under prediction bound. It can be noticed from Figs. 2 and 3 that the $R^{2}$ values in SOFM2 model are smaller than those in SOFM1 model, indicating the higher prediction performance of the SOFM1 model in predicting $F_{\mathrm{s}}$ values of the artificial slope than SOFM2 model.

The $F_{\mathrm{s}}$ values calculated from the Simplified Bishop Method [4] were compared with the $F_{\mathrm{s}}$ values predicted from the SOFM3 model, as depicted in Fig. 4 for training, validation, and testing samples. The solid diagonal line in Fig. 4 represents a perfect prediction line. The lower line represents a $100 \%$ over prediction bound and the upper line represents a $50 \%$ under prediction bound. Figs. 2 and 4 demonstrate that the $R^{2}$ values in SOFM3 model are very smaller than those in SOFM1 model, yielding the higher performance of SOFM1 model in predicting $F_{\mathrm{s}}$ values of the artificial slope than SOFM3model.

As mentioned earlier, SOFM1, SOFM2, and SOFM3 models have different neighborhood shapes, namely, SquareKohonenful, LineKohonenful, and DiamondKohenenful, respectively. When comparing the performance of the SOFM models (Figs. 2 to 4), the SOFM1 model yields more reliable predictions than both SOFM2 and SOFM3 models. This result indicates both the importance of the selection of the neighborhood shape and the use of SquareKohonenful neighborhood shape while developing the SOFM models as observed by Tai et al. [30]. As a result, the utilize of the SOFM2 and SOFM3 models with neighborhood shapes, namely 
Erzin T. et al.: The use of Self-Organizing Feature Map networks for...
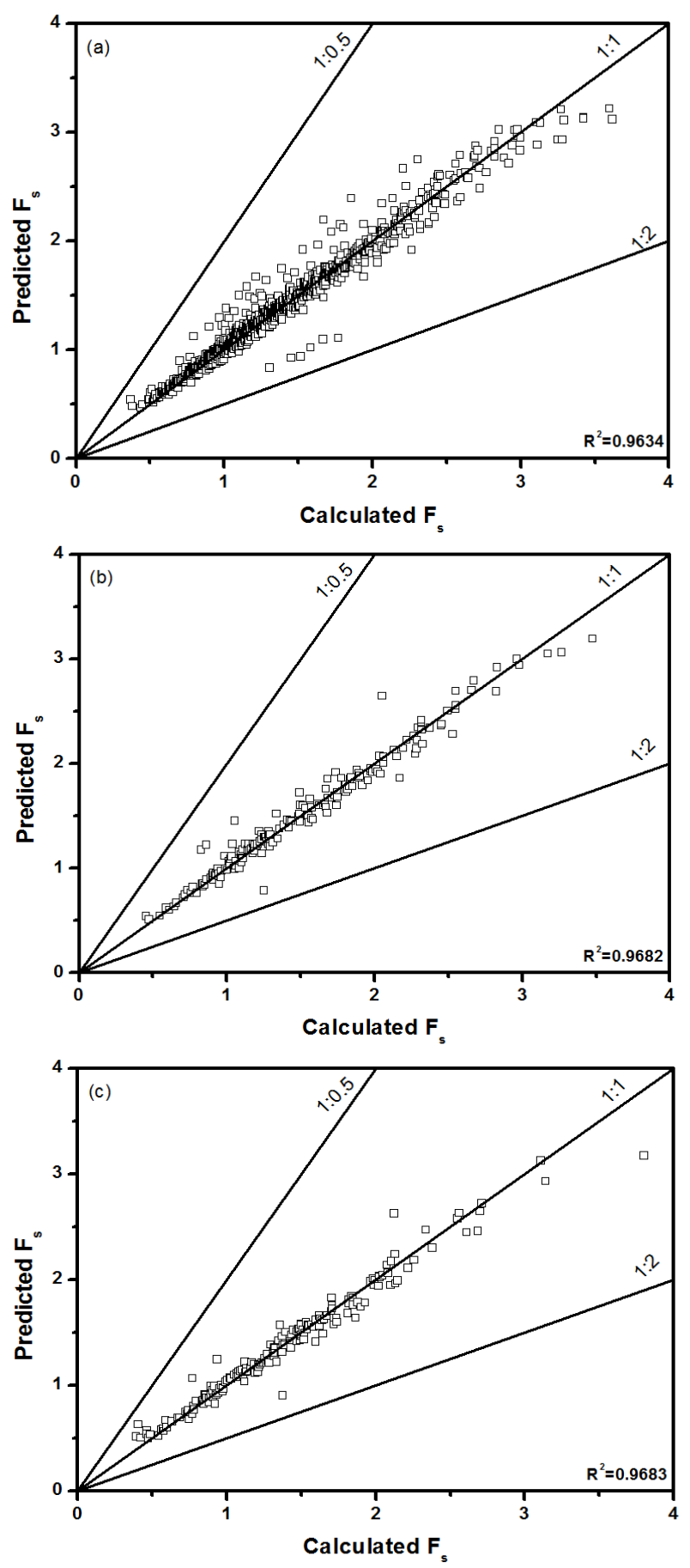

Fig. 2 The comparison of the calculated $F_{\mathrm{s}}$ values with the predicted $F_{\mathrm{s}}$ values from the SOFM1 model for (a) training, (b) validation and (c) testing samples. 
Neural Network World 5/2016, 461-475
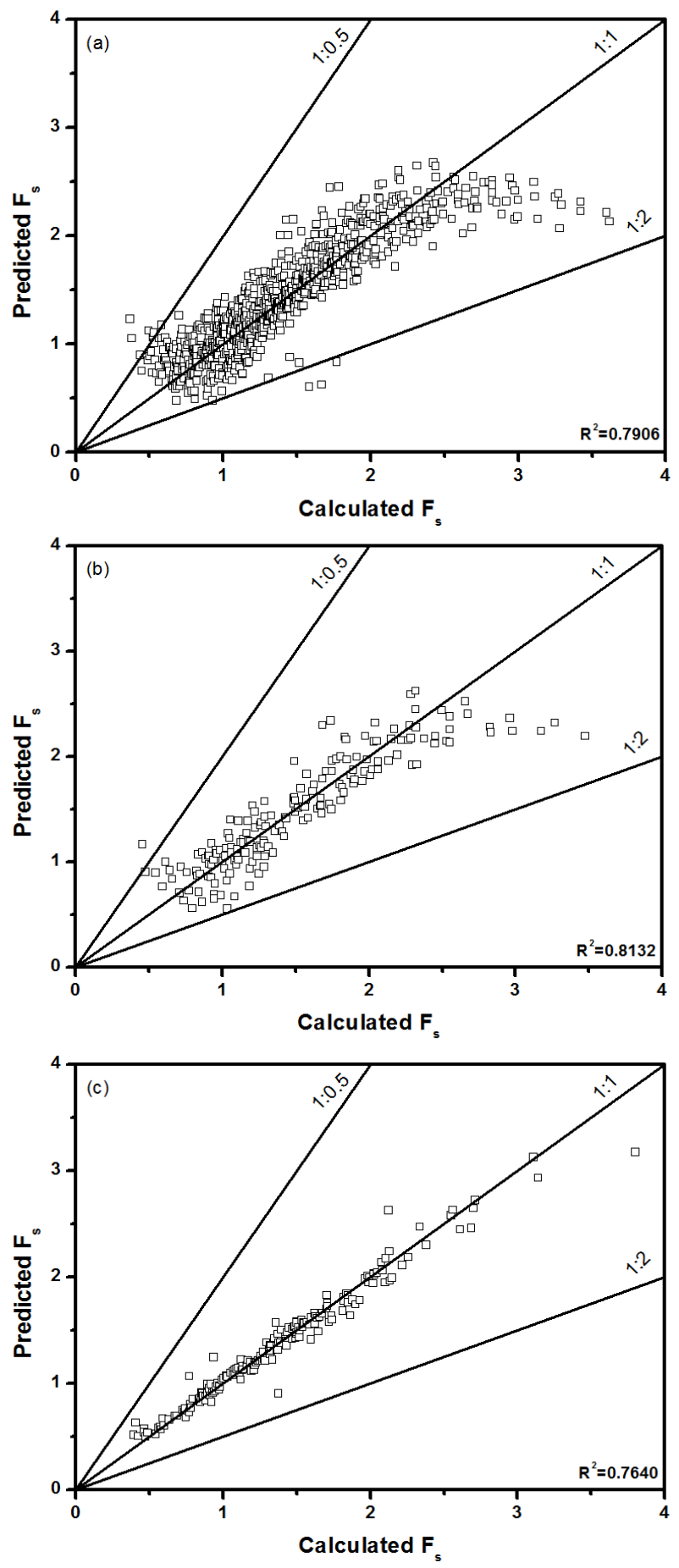

Fig. 3 The comparison of the calculated $F_{\mathrm{s}}$ values with the predicted $F_{\mathrm{s}}$ values from the SOFM2 model for (a) training, (b) validation and (c) testing samples. 
LineKohonenful, and DiamondKohenenful is not recommended at the preliminary stage of designing the homogeneous finite slope subjected to earthquake forces considered in this study.

When Erzin and Cetin [7] developed a multiple regression (MR) model (Eq. 7) by utilizing the data sets used while developing the SOFM models to predict the $F_{\mathrm{s}}$ values:

$$
F_{\mathrm{s}}=1.247-2.430 k_{\mathrm{h}}-0.030 \gamma+0.024 c+0.031 \varphi .
$$

The $F_{\mathrm{s}}$ values calculated from the Simplified Bishop Method [4] were also compared with the $F_{\mathrm{s}}$ values predicted from the MR model in Fig. 5 for training, validation, and testing samples. The solid diagonal line in Fig. 5 represents a perfect prediction line. The lower line represents a $100 \%$ over prediction bound and the upper line represents a $50 \%$ under prediction bound. It can be noted from the Figs. 2 and 5 that the $R^{2}$ values in the MR model are smaller than those in the SOFM1 model, which indicates the higher performance of the SOFM1 model in predicting $F_{\mathrm{S}}$ values of the artificial slope. When compared the prediction performances of MR, SOFM2, and SOFM3 models (Figs. 3 to 5), it can be also noticed that MR model yielded the higher performance than both SOFM2 and SOFM3 models in predicting $F_{\mathrm{s}}$ values of the artificial slope.

Variance accounted for (VAF), given by Eq. (8), and the root mean square error (RMSE), given by Eq. (9), were also calculated in order to evaluate the performance of the prediction capacity of predictive models developed in the study, as employed by previous researchers $[6,8-14]$ :

$$
\begin{aligned}
& \mathrm{VAF}=\left[1-\frac{\operatorname{var}(y-\hat{y})}{\operatorname{var}(y)}\right] \times 100, \\
& \mathrm{RMSE}=\sqrt{\frac{1}{N} \sum_{i=1}^{N}\left(y_{i}-\hat{y}_{i}\right)^{2}},
\end{aligned}
$$

where var denotes the variance, $y$ is the measured value, $\hat{y}$ is the predicted value, and $N$ is the number of the sample. If VAF is $100 \%$ and RMSE is 0 , the model is treated as excellent. The performance indices calculated for the three SOFM models developed in this study and the MR model are listed in Tab. III, which shows that the SOFM1 model has exhibited the higher prediction performance than the other SOFM models (SOFM2 and SOFM3) and the MR model based on the computed performance indices.

In addition, a graph between the scaled percent error, SPE, (as given by Eq. (10) and employed by Kanibir et al. [20] and Erzin et al. [14]) and the cumulative frequency was also drawn, as given in Fig. 4 for the three SOFM models and the MR model to assess the performance of the models:

$$
S P E=\frac{\left(F_{\mathrm{sp}}-F_{\mathrm{sc}}\right)}{\left(\left(F_{\mathrm{sc}}\right)_{\max }-\left(F_{\mathrm{sc}}\right)_{\min }\right)},
$$

where $F_{\mathrm{sp}}$ and $F_{\mathrm{sc}}$ are the predicted and the calculated factor of safety values; and $\left(F_{\mathrm{sc}}\right)_{\max }$ and $\left(F_{\mathrm{sc}}\right)_{\min }$ are the maximum and minimum calculated factor of safety values, respectively. It can be noticed from Fig. 6 that about $92 \%, 57 \%$, and $23 \%$ of the factor of safety values predicted from the SOFM1, SOFM2, and SOFM3 
Neural Network World 5/2016, 461-475
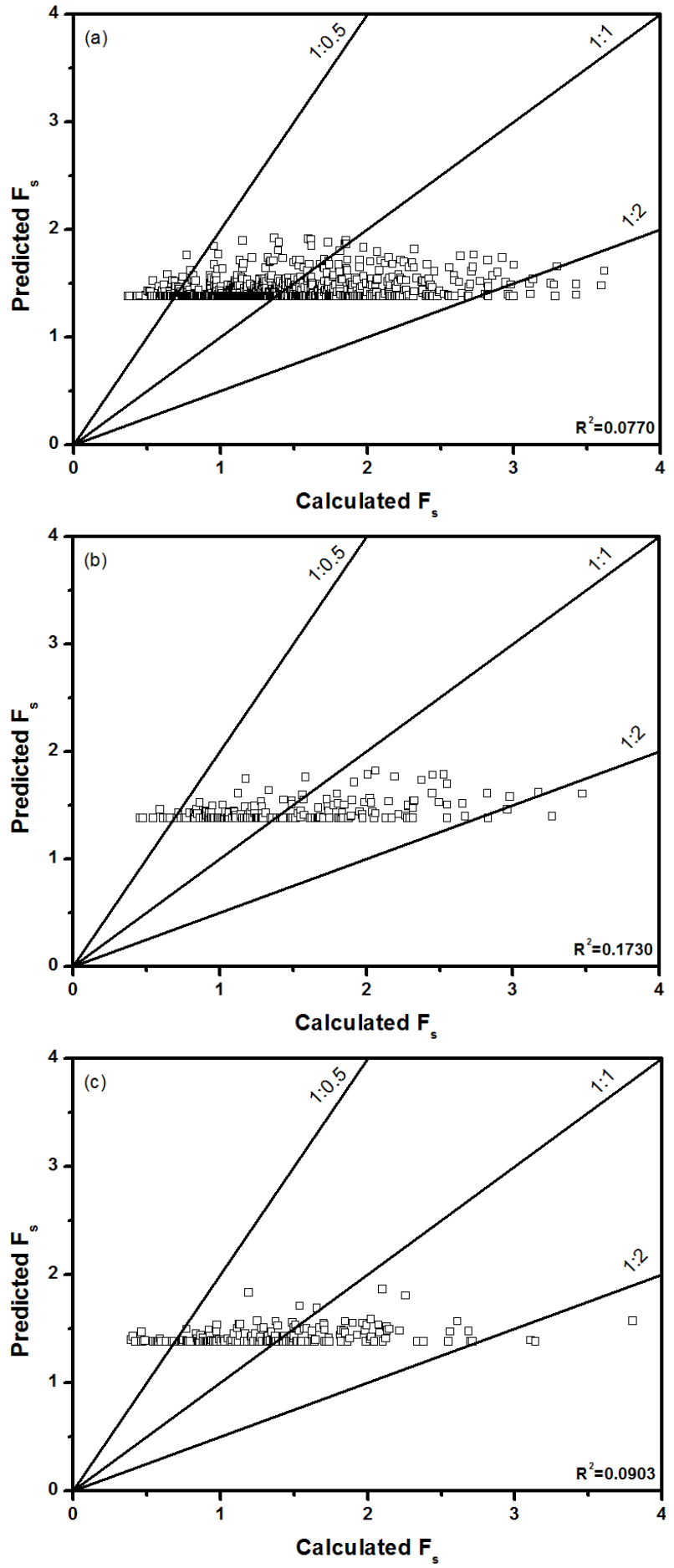

Fig. 4 The comparison of the calculated $F_{\mathrm{s}}$ values with the predicted $F_{\mathrm{s}}$ values from the SOFM3 model for (a) training, (b) validation and (c) testing samples. 
Erzin T. et al.: The use of Self-Organizing Feature Map networks for...
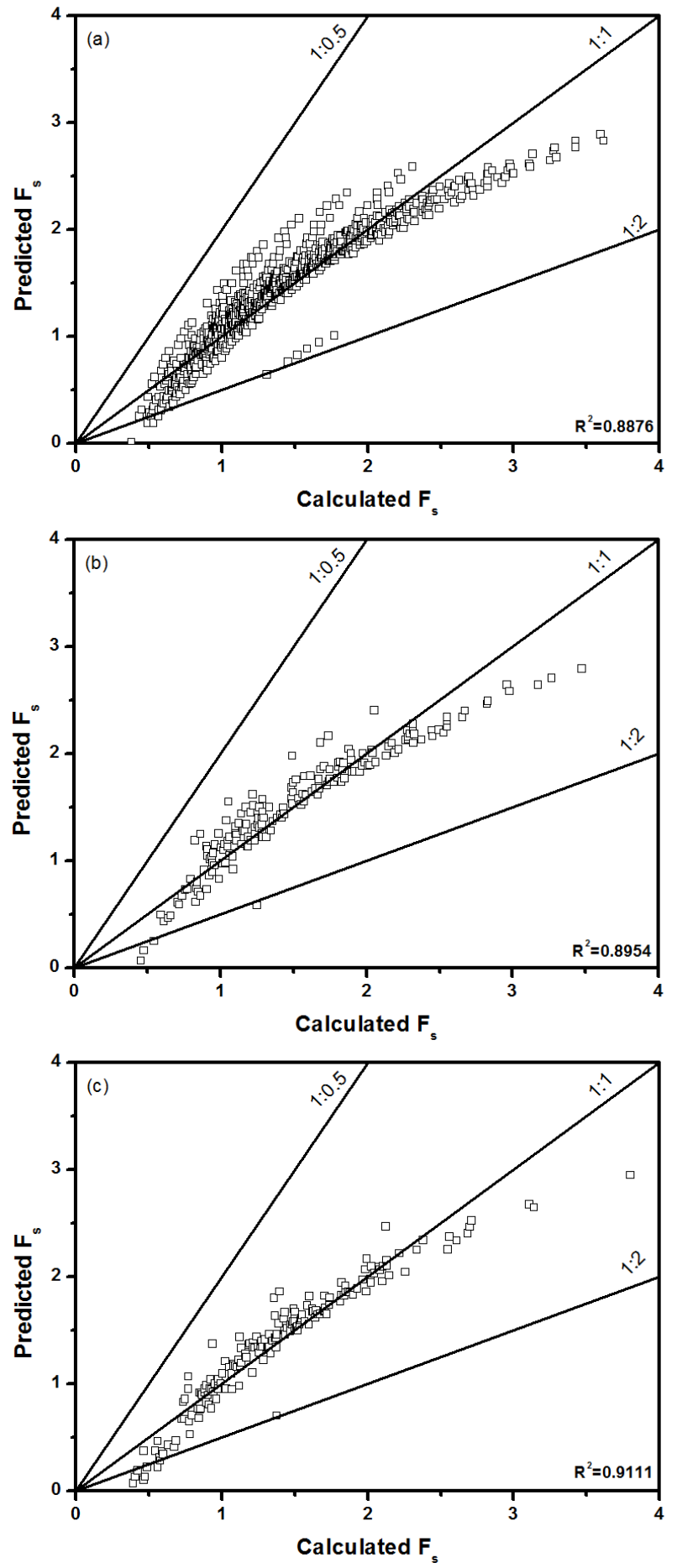

Fig. 5 The comparison of the calculated $F_{\mathrm{s}}$ values with the predicted $F_{\mathrm{s}}$ values from the MR model for (a) training, (b) validation and (c) testing samples. 
Neural Network World 5/2016, 461-475

\begin{tabular}{llcccc}
\hline Model & Data & $R^{2}$ & MAE & RMSE & VAF [\%] \\
\hline \multirow{4}{*}{ SOFM1 } & Training set & 0.9634 & 0.07 & 0.11 & 96.34 \\
& Validation set & 0.9682 & 0.07 & 0.11 & 96.78 \\
& Testing set & 0.9683 & 0.06 & 0.11 & 96.68 \\
& Training set & 0.7906 & 0.19 & 0.27 & 79.06 \\
SOFM2 & Validation set & 0.8132 & 0.19 & 0.27 & 81.20 \\
& Testing set & 0.7644 & 0.20 & 0.28 & 76.38 \\
\multirow{2}{*}{ SOFM3 } & Training set & 0.0770 & 0.44 & 0.56 & 6.76 \\
& Validation set & 0.1730 & 0.46 & 0.58 & 11.10 \\
& Testing set & 0.0903 & 0.43 & 0.56 & 6.58 \\
MR & Training set & 0.8876 & 0.14 & 0.19 & 88.76 \\
& Validation set & 0.8954 & 0.15 & 0.20 & 89.36 \\
& Testing set & 0.9111 & 0.12 & 0.17 & 90.90 \\
\hline
\end{tabular}

Tab. III Performance indices $\left(R^{2}, M A E, R M S E\right.$, and VAF) of the SOFM1, SOFM2, SOFM3 and MR models.

models, respectively, developed a fall into $\pm 5 \%$ of the SPE, indicating a perfect estimate for the $F_{\mathrm{S}}$ value of the slope from the SOFM1 model when compared with the SOFM2 and SOFM3 models. As shown in Fig. 6, about $72 \%$ of factor of safety values predicted from the MR model developed a fall into $\pm 5 \%$ of the SPE. It can be noticed from Fig. 6 that SOFM1 model yielded the highest estimate for the

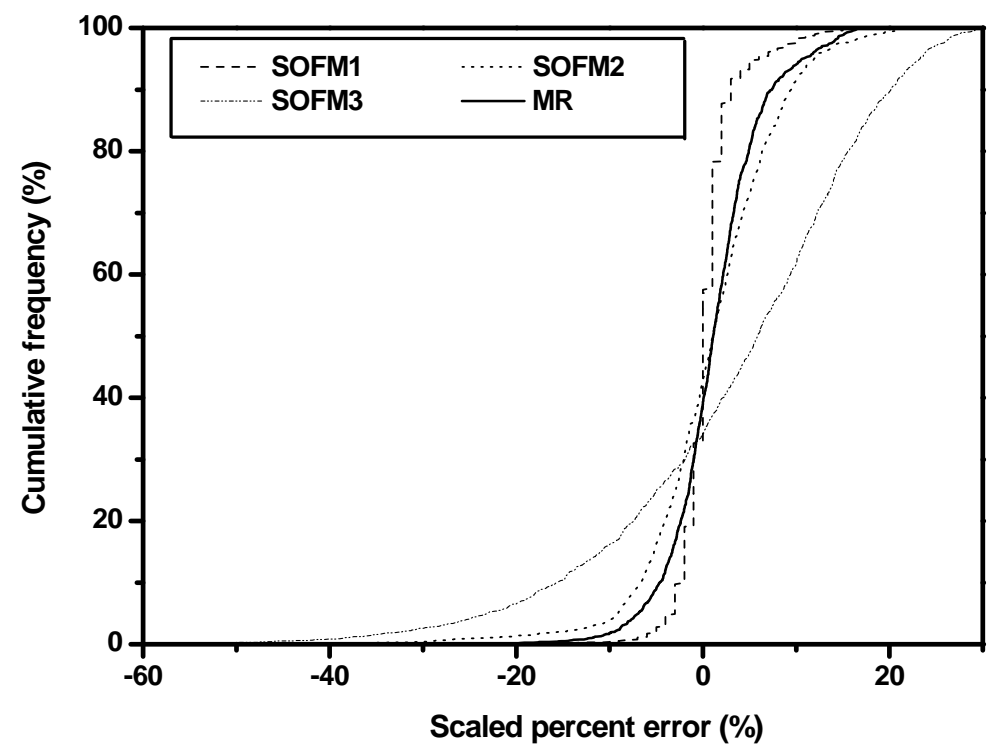

Fig. 6 The relationship between the scaled percent error and cumulative frequency for SOFM1, SOFM2, SOFM3, and MR models. 
$F_{\mathrm{S}}$ value than the other SOFM models (SOFM2 and SOFM3) and the MR model. Therefore, the $F_{\mathrm{s}}$ value of the widely-used artificial slope utilized in this study could be predicted from easily determined soil properties and seismic coefficient using the SOFM1 model, with acceptable accuracy, at the preliminary stage of designing the artificial slope.

\section{Conclusions}

In this study, the performance of three different Kohonen Self Organization Feature Map (SOFM) network models with different neighborhood shapes to predict the critical factor of safety $\left(F_{\mathrm{s}}\right)$ value of the widely-used artificial slope subjected to earthquake forces has been investigated and compared. For this purpose, the data sets reported in Erzin and Cetin [7], including the $F_{\mathrm{s}}$ values of the artificial slope calculated by using the simplified Bishop method [4], were utilized in the development of the three SOFM models denoted as SOFM1, SOFM2, and SOFM3 having neighborhood shapes, namely, SquareKohonenful, LineKohonenful, and DiamondKohenenful, respectively. The SOFM models included four input parameters, namely, bulk unit weight $(\gamma)$, cohesion $(c)$, and angle of internal friction $(\varphi)$ of the layer beneath the ground surface and seismic coefficient $(k)$ and one output parameter, $F_{\mathrm{s}}$. The results obtained from the three SOFM models were compared with those obtained from the calculations. It is found that the $F_{\mathrm{s}}$ values predicted from the SOFM1 model match with the calculated $F_{\mathrm{s}}$ values much better than both SOFM2 and SOFM3 models. This result indicated both the importance of the neighborhood shape and the use of SquareKohonenful neighborhood shape while developing an SOFM model as observed by past researcher [30]. Further, the SOFM1 model with SquareKohonenful neighborhood shape is found to yield better predictions than the MR model developed and reported by Erzin and Cetin [7].

In addition, the performance indices such as the determination coefficient, variance account for, mean absolute error, root mean square error, and the scaled percent error were used to assess the prediction capacity of the SOFM models developed. The study demonstrates that the SOFM1 model is able to predict the $F_{\mathrm{s}}$ value of the artificial slope, quite efficiently, and is superior to the SOFM2 and SOFM3. Thus, the SOFM1 model can be used to predict the $F_{\mathrm{s}}$ value of the widelyused artificial slope subjected to earthquake forces quite easily and efficiently.

\section{References}

[1] BAKER R., SHUKHA R., OPERSTEIN V., FRYDMAN S. Stability charts for pseudostatic slope stability analysis. Soil Dyn Earthq Eng. 2006, 26, pp. 813-823, doi: 10.1016/j. soildyn.2006.01.023.

[2] BAKIR B.S., AKIŞ E. Analysis of a highway embankment failure associated with the 1999 Düzce, Turkey. Soil Dynamics and Earthquake Engineering. 2005, 25, pp. 251-260, doi: 10. 1016/j. soildyn.2003.05.001.

[3] BANDINI P., LOUKIDIS D., SALGADO R. Limit analysis of seismically loaded slopes. In: Proc. Of the $16^{\text {th }}$ International Conference of the International Association for Computer Methods and Advances in Geomechanics, Toronto, Italy, 2005. 


\section{Neural Network World 5/2016, 461-475}

[4] BISHOP A.W. The use of the slip circle in the stability analysis of slopes. Géotechnique. 1955, 5(1), pp. $7-17$, doi: 10.1680/geot.1955.5.1.7.

[5] CETIN T. Developing a computer program for analysis of slope stability and comparing different analysis method. MSc. Thesis, Celal Bayar University Manisa, 2014. In Turkish.

[6] ERZIN Y. Artificial neural networks approach for swell pressure versus soil suction behavior. Canadian Geotechnical Journal. 2007, 44(10), pp. 1215-1223, doi: 10.1139/T07-052.

[7] ERZIN Y., CETIN T. The use of neural networks for the prediction of the critical factor of safety of an artificial slope subjected to earthquake forces. Scientia Iranica. 2012, 19(2), pp. 188-194, doi: 10.1016/j.scient.2012.02.008

[8] ERZIN Y., CETIN T. The prediction of the critical factor of safety of homogeneous finite slopes using neural networks and multiple regressions. Computers and Geosciences Journal. 2013, 51, pp. 305-313, doi: 10.1016/j.cageo.2012.09.003.

[9] ERZIN Y., CETIN T. The prediction of the critical factor of safety of homogeneous finite slopes subjected to earthquake forces using neural networks and multiple regressions. International Journal of Geomechanics. 2014, 6(1), pp. 1-15, doi: 10.12989/gae.2014.6.1.001.

[10] ERZIN Y., GUNES N. The prediction of swell percent and swell pressure by using neural Networks. Computers \& Mathematics with Applications. 2011, 16(2), pp. 425-436.

[11] ERZIN Y., RAO B.H., SINGH D.N. Artificial neural networks for predicting soil thermal Resistivity. International Journal of Thermal Sciences. 2008, 47, pp. 1347-1358, doi: 10. 1016/j.ijthermalsci.2007.11.001.

[12] ERZIN Y., GUMASTE S.D., GUPTA A.K., SINGH D.N. ANN models for determining hydraulic conductivity of compacted fine grained soils. Canadian Geotechnical Journal. 2009, 46, pp. 955-968, doi: 10.1139/T09-035.

[13] ERZIN Y., RAO B.H., PATEL A., GUMASTE S.D., GUPTA A.K., SINGH D.N. Artificial neural network models for predicting of electrical resistivity of soils from their thermal resistivity. International Journal of Thermal Sciences. 2010, 49, pp. 118-130, doi: 10.1016/j.ijthermalsci.2009.06.008.

[14] ERZIN Y., PATEL A., SINGH D.N., TIGA M.G., YILMAZ I., SRINIVAS K. Investigations on factors influencing the crushing strength of some Aegean sands. Bulletin of Engineering Geology and the Environment. 2012, 71, 529-536, doi: 10.1007/s10064-012-0424-9.

[15] FELLENIUS W. Calculation of the stability of earth dams. In: Transactions of the $2^{\text {nd }}$ congress on large dams, Washington DC. International Commission on Large Dams (ICOLD), Paris. 1936, 4, pp. 445-463.

[16] FRASER S.J., DICKSON B.L. A new method for data integration and integrated data interpretation: Self-organizing Maps. In: Proceedings of Exploration 0\%: Fifth Decennial International Conference on Mineral Exploration, edited by B. Milkereit, 2007, pp. 907-910.

[17] GAVIN J., BOWDEN G.C. Input determination for neural network models in water resources applications. Part 1 - background and methodology. Journal of Hydrology. 2005, 301, pp. 75-92, doi: 10.1016/j.jhydrol.2004.06.021.

[18] HACK R., ALKEMA D., KRUSE G.A.M., LEENDERS N., LUZI L. Influence of earthquakes on the stability of slopes. Engineering Geology. 2007, 9, pp. 4-15, doi: 10.1016/j.enggeo. 2006.12 .016

[19] JANBU N. Application of composite slip surface for stability analysis. In: Proceedings of Europan conference on stability of earth slopes, Stockholm, Sweden. 1956, pp. 43-49.

[20] KANIBIR A., ULUSAY R., AYDAN Ö. Liquefaction-induced ground deformations on a lake shore (Turkey) and empirical equations for their prediction. In: Proceedings of the 10th Congress of the International Association for Engineering Geology and the Environment (IAEG), Nottingham, United Kingdom. paper 362. Available from: http://iaeg2006. geolsoc.org.uk/cd/papers/iaeg_362.pdf.

[21] KOHONEN T. Self-organization and associate memory. $2^{\text {nd }}$ ed. Berlin: Springer-Verlag, 1989.

[22] KRISHNAMOORTHY A. Factor of safety of a slope subjected to seismic load. Electronic Journal of Geotechnical Engineering. 2007, 12(E). 
Erzin T. et al.: The use of Self-Organizing Feature Map networks for...

[23] MANOUCHEHRIAN A., GHOLAMNEJAD J., SHARIFZADEH M. Development of a model for analysis of slope stability for circular mode failure using genetic algorithm. Environmental Earth Sciences. 2014, 71, pp. 1267-1277, doi: 10.1007/s12665-013-2531-8.

[24] MOHAMED T., KASA A., MUKHLISiN M. Prediction of Slope Stability Using Statistical Method and Fuzzy Logic. The Online Journal of Science and Technology. 2012, 2(4), pp. $68-73$.

[25] MORGENSTERN N.R., PRICE V.E. The analysis of the stability of general slip surfaces. Géotechnique. 1965, 15, pp. 70-93, doi: 10.1016/0022-4898(66)90182-0.

[26] NIKOO M., ZARFAM P., SAYAHPOUR H. Determination of compressive strength of concrete using Self Organization Feature Map (SOFM). Engineering with Computers. 2015, 31, pp. 113-121, doi: 10.1007/s00366-013-0334-x.

[27] NURIC A., NURIC S., KRICAK L., HUSAGIC R. Numerical methods in analysis of slope stability. International Journal of Science and Engineering Investigations. 2013, 2(24), pp. 41-48.

[28] SARMA S.K. Stability analysis of embankments and slopes. Journal of Geotechnical Engineering. 1973, 105, pp. 1511-1524,doi: 10.1680/geot.1973.23.3.423.

[29] SPENCER E. A method of analysis of the stability of embankments assuming parallel interslice forces. Géotechnique. 1967, 17, pp. 11-26, doi: 10.1680/geot.1967.17.1.11.

[30] TAI D. W.-S., WU H.-J., LI P.-H. Effective e-learning recommendation system based on selforganizing maps and association mining. The Electronic Library. 2008, 26(3), pp. 329-344, doi: $10.1108 / 02640470810879482$.

[31] TAYLOR D.W. Stability of earth slopes. J Boston Soc Civil Engineers. 1937, 23, pp. 197-247. Reprinted in contributions to soil mechanics 1925-1940. Boston Society of Civil Engineers. 1960, pp. 337-386, doi: 10.1680/geot.1960.10.4.129.

[32] WANG H.B., XU W.Y., XU R.C. Slope stability evaluation using back propagation neura networks. Engineering Geology. 2005, 80, pp. 302-315, doi: 10.1016/j . enggeo.2005.06.005

[33] ZHAO Y., TONG Z.Y., LÜ Q. Slope Stability Analysis Using Slice-Wise Factor of Safety. Mathematical Problems in Engineering. 2014, pp. 6, doi: 10.1155/2014/712145. 